\title{
Investigating the isotopic composition of mercury and lead in epiphytic lichens from South-western France (Pyrénées-Atlantiques) to better constrain the spatial variability of their atmospheric transport and deposition
}

\author{
J. P. G. Barre ${ }^{1}$, D. Amouroux ${ }^{1}$, G. Deletraz ${ }^{2}$, S. Bérail ${ }^{1}$, H. Pinaly ${ }^{1}$, O. F. X. Donard ${ }^{1}$ and T. $\operatorname{Tran}^{2}$ \\ ${ }^{1}$ Laboratoire de Chimie Analytique Bio-Inorganique et Environnement (LCABIE), Institut des Sciences Analytiques et \\ de Physico-Chimie pour l'Environnement et les Matériaux (IPREM), UMR 5254 CNRS, Université de Pau et des Pays \\ de 1'Adour, Hélioparc 2, av P Angot, 64053 Pau Cedex 9, France, julien.barre@etud.univ-pau.fr, david.amouroux@univ- \\ pau.fr \\ ${ }^{2}$ Laboratoire Société, Environnement et Territoire (SET), UMR 5603 CNRS - Université de Pau et des Pays de l'Adour, \\ Pau, France, gaelle.deletraz@univ-pau.fr
}

\begin{abstract}
The geographical variability of the elemental concentration and isotopic composition of mercury and lead was evaluated in epiphytic lichens collected over a mesoscale area (Pyrenees-Atlantiques, Southwestern France). The sampling points have been selected according to different parameters in order to represent the main land use classification of the investigated territory (urban, industrial, agricultural and forestal zones). Total concentrations of $\mathrm{Hg}$ are homogenous over the territory (mean $0.14 \mathrm{mg} / \mathrm{kg}$ dry weight) and reflect the European atmospheric anthropogenic background deposition. A significant trend is observed for lead concentrations between anthropogenized areas $(\sim 11 \mathrm{mg} / \mathrm{kg})$ and remote areas $(\sim 6 \mathrm{mg} / \mathrm{kg})$, mainly due to local road traffic and industrial inputs. The isotopic composition of $\mathrm{Hg}$ reveals a relatively homogeneous signature specific of remote areas, while the lead isotopic composition is distributed along two distinct origins: past leaded gasoline and geogenic background. This study shows that the spatial concentration variability observed is globally consistent with the isotopic signatures of $\mathrm{Hg}$ and $\mathrm{Pb}$ recorded in lichens which partly explain the origin of these two metallic contaminants.
\end{abstract}

Key words: isotopic composition, lichens, lead, mercury, atmospheric deposition, geographical variability

\section{Introduction}

Atmospheric concentrations of mercury and lead are decreasing in France and Europe for many years (Pacyna, et al., 2009; CITEPA, 2009). In addition, more than 50\% of contamination (EMEP 2011) has a transboundary origin which implies the integration of different pollution sources. The Pyrénées-Atlantiques territory (SW France) exhibits different land uses like urban, rural, farming, mountain and coastal area. It can be characterized by relatively low population density exhibiting few antropogenic pollution sources to the atmosphere and receiving mainly atmospheric metal inputs from long range transport.

Evaluation of atmospheric contamination by lead and mercury in this environment subject to low local pollution might be unraveled by the use of emerging multi-isotopic signatures bioaccumulated in lichens (Szczepaniak, et al., 2003; Carignan, et al., 1995).
Mercury is a transboundary contaminant (Bergquist, et al., 2009; Estrade, et al., 2010) undergoing various reactions during transport (photo-reduction, ...) which impact its isotopic composition (Bergquist, et al., 2009; Sonke, 2011) and cause a fractionation to potentially track local and global sources of contamination (Bergquist, et al., 2009; Estrade, et al., 2010) and transformation processes involved.

Atmospheric lead is less reactive, its isotopic composition does not vary significantly during its atmospheric transport (Veschambre, et al., 2008), and is indicative of its point of extraction and/or emission. Banning the use of leaded gasoline had led to a sharp decrease in its concentration and a recovery of the isotopic composition of natural sources. It is therefore necessary to actually improve our knowledge on the major contemporary atmospheric sources of lead, especially in less polluted areas. . 
Furthermore the use of geographical information system (GIS) allows the linking of quantitative components (amount of contaminant deposited) and qualitative (origin of emissions: local pollution, long distance, human or natural) of these two pollutants in a large variety of geographic variables (land use, population density, topography, gradient of distance to the ocean).

The combination of these tools may thus help to deduce the origin of atmospheric contamination and to understand the different processes involved and their transport and deposition.

\section{Materials and Methods}

\section{Sampling Sites}

The samples were collected in the department of Pyrenees-Atlantiques using a GIS tool to determine their position with different parameters (land use balanced by its contribution to the emissions, distance to the ocean, population density ...). The aim of this sampling strategy was to be the most representative of our territory. The collection was made during two campaigns in November 2010 and June 2011. Some sites were performed during the two campaigns in order to make a seasonal comparison. The samples were collected at 100 meters of any road to prevent the redeposition of particles.

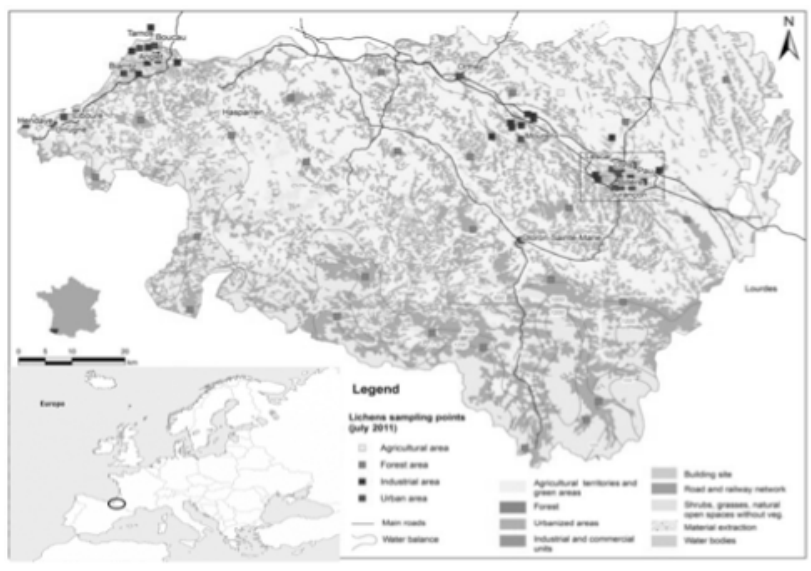

Fig. 1. Sampling sites are represented.

In order to reflect the biological diversity of each site, various lichen species were collected and mixed such as Evernia Prunastri, Parmelia Sulcata, Parmelia Caperata, Hypogymnia Physodes Moreover, selected sampling sites were monitored at different season to evaluate the seasonal variability. On each sites, total mercury and lead concentration and also isotopic compositions were measured and compared with literature dataset.

\section{Sample collection}

The samples were collected with gloves and stainless steel tools at a height between 1 and 2 meters on the tree bark according to the French norm NF X903-43 (AFNOR, 2008). They were immediately packed in zip- lock PE bags and placed into a freezer $\left(-20^{\circ} \mathrm{C}\right)$ back to the laboratory. All lichens concentrations and isotopic composition were validated by two reference materials: CRM BCR 482 (Lichen: Pseudevernia furfuracea) and IAEA 336 (Evernia prunastri).

\section{Sample preparation}

Lichens are freeze dried, and subsequently separated from their substratum (bark) and ground with a mixer mill in Teflon bowl. $1 \mathrm{~g}$ of lichens are digested in $90 \mathrm{~mL}$ quartz tube with $5 \mathrm{~mL}$ of sub-boiled $\mathrm{HNO}_{3}$ in a high pressure asher (HPA-S, Anton Paar) at $300^{\circ} \mathrm{C}$ and 130 bars for 3 hours. For the determination of the lead isotopic composition, $1.4 \mathrm{~mL}$ of digested lichens is treated on ion exchange resin (Cloquet, Carignan et Libourel 2006, Manhès, Minster et Allègre 1978), and thallium (Tl NIST SRM 997) is added as internal standard isotopically certified for correcting instrumental mass bias.

\section{Elemental analysis}

The powder of lichens samples are analyzed by direct total analyses techniques to determine the concentrations in lead and mercury. Mercury concentrations are determined by an advance mercury analyzer (AMA 254, LECO). The analyses of the lead concentration are performed by atomic absorption spectrometry with a graphite furnace (GFAAS ContrAA 700, Analytik Jena) and by mass spectrometry (ICP MS X2, Thermo). Others metallic elements were analyzed such as $\mathrm{Cu}, \mathrm{Cd}, \mathrm{V}, \mathrm{Sn}$ ... by Q-ICP-MS (X2, Thermo). Copper and cadmium were also analyzed on GFAAS

\section{Isotopic analysis}

The determination of isotopic composition of $\mathrm{Hg}$ is determined on MC-ICP-MS (Nu Plasma, Nu Instruments) coupled to a cold vapor generation $(\mathrm{CVG})$. All samples are analyzed at low concentration $\left([\mathrm{Hg}]_{\mathrm{T}}=1 \mathrm{ppb}\right)$ in order to minimize the matrix effects. To correct all the results, sample standard bracketing (SSB) is made with a standard of mercury (NIST SRM 3133) and the mass bias correction is realized with thallium (NIST SRM 997) (Blum, et al., 2007; Estrade, et al., 2010b).

Isotopic analyses for $\mathrm{Pb}$ were performed with conventional pneumatic nebulization Neb-MC-ICP-MS ( $\mathrm{Nu}$ Plasma, $\mathrm{Nu}$ Instruments) at a concentration of 200 $\mathrm{ppb}$ for the most concentrated samples and at $30 \mathrm{ppb}$ with a desolvating nebulizer (DSN-100, Nu Instruments) for the less concentrated samples. Before this analysis, the lead is extract by a resin (Dowex 1X8) according to the protocol of Manhès et al.(1978). Then solutions are analyzed by quadrupole ICP-MS (Q-ICP-MS) to determine the recuperation percentage of the extraction.

\section{Results}

\section{Method validation}

All methods used are validated by analyzing reference materials (see Figure 2(a)). All the results obtained are in 
Fig. 2. (a) Measurement of Concentration in Lead, mercury, copper and cadmium of Lichen reference material BCR 482 and IAEA 336, (b) Comparison between isotopic compositions measured for BCR 482 and UM-Almàden with Estrade et al. (2010a).

(a)

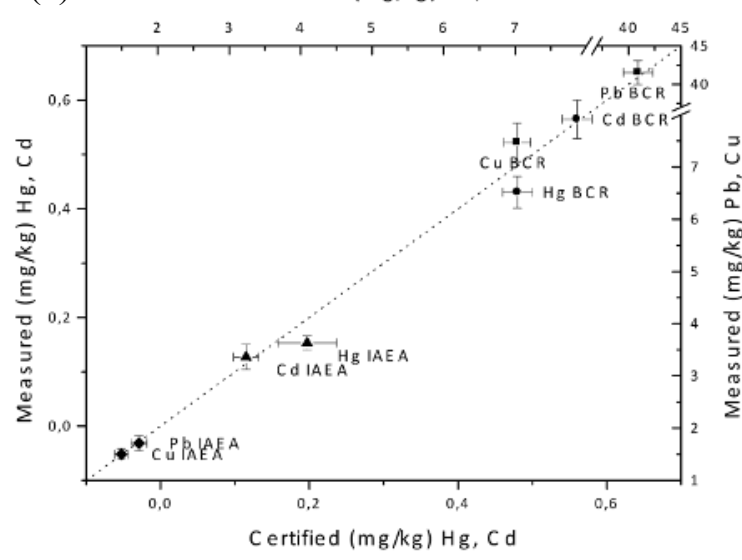

(b)

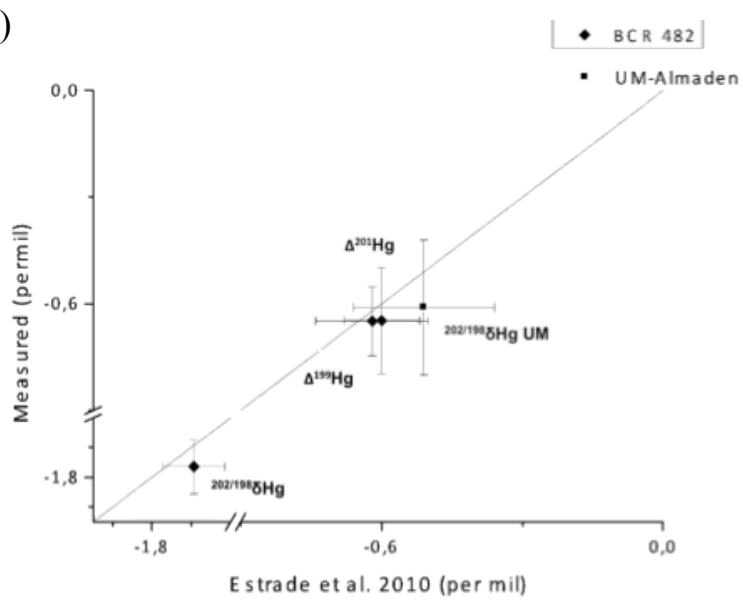

Table 1. Concentration in $\mathrm{mg} / \mathrm{kg}$ in Mercury and Lead according to the land use

\begin{tabular}{|c|c|c|c|c|c|c|c|c|}
\hline & \multicolumn{4}{|c|}{ Hg } & \multicolumn{4}{|c|}{$\mathbf{P b}$} \\
\hline & \multicolumn{4}{|c|}{ Total concentration by AMA 254 (mg/kg) } & \multicolumn{4}{|c|}{ Total concentration by GFAAS $(\mathrm{mg} / \mathrm{kg})$} \\
\hline & Average & $S D$ & Min. & $\operatorname{Max}$ & Average & $S D$ & Min. & $\operatorname{Max}$. \\
\hline Urban Zone $(n=28)$ & 0.13 & 0.04 & 0.07 & 0.21 & 10.61 & 7.64 & 1.62 & 35.76 \\
\hline Industrial Zone of $P-A(n=28)$ & 0.15 & 0.05 & 0.04 & 0.28 & 12.92 & 10.47 & 0.72 & 43.29 \\
\hline Forestal Zone $(n=29)$ & 0.14 & 0.03 & 0.07 & 0.19 & 6.30 & 4.42 & 0.26 & 18.90 \\
\hline Agricultural Zone $(n=29)$ & 0.14 & 0.04 & 0.08 & 0.21 & 5.91 & 4.78 & 1.52 & 26.75 \\
\hline
\end{tabular}

good agreement with the reference values. For isotopic composition, the average of UM-Almàden and BCR 482 are issued of different session between May 2011 and March 2012. The results are compared with those obtain by Estrade et al. (2010a) (see Figure 2(b)).

\section{Variability $\mathrm{Hg}$ and $\mathrm{Pb}$ concentration in lichen samples}

The total analyses of $\mathrm{Hg}$ and $\mathrm{Pb}$ concentration do not exhibit any point source of contamination (see Table 1). The concentrations of mercury are homogenous (average about $0.14 \mathrm{mg} / \mathrm{kg}$ ) between the different land use areas. On the contrary, lead concentrations exhibit higher contamination in the industrial and urban zones, which can be explained by the road traffic and several industrial activities (7).

\section{Variability of $\mathrm{Hg}$ and $\mathrm{Pb}$ Isotopic composition in lichen samples}

Isotopic compositions of $\mathrm{Hg}$ are calculated relative to NIST SRM 3133 and follow the recommendation of Blum et al. (2007). Mass dependent $\left({ }^{202 / 198} \delta\right)$ and mass independent $\left(\Delta^{199} \mathrm{Hg}\right)$ fractionation exhibit the same range within the different land use areas (see Figure 3(a)) and are also in agreement with the values obtained by Carignan et al. (2009) for remote areas.
Isotopic composition of mercury gives thus more information about the origin of atmospheric $\mathrm{Hg}$ scavenged by the lichens. The plot of $\Delta 199$ vs. $\Delta 201$ exhibits a slope ca. 1, which suggests that photoreduction is a major process involved (Bergquist, et al., 2009; Sonke, 2011).

For isotopic composition lead of $\mathrm{Pb}$, results presented in Figure 3(b) exhibit a primary trend between the different land use areas. The plot of ${ }^{208 / 206} \mathrm{~Pb}$ vs. ${ }^{207 / 206} \mathrm{~Pb}$ show a classical distribution of lead along a line between two poles: leaded European gasoline and geogenic background (Veschambre, et al., 2008). Moreover, the trend clearly distinguish the remote sites (Agricultural and forestal zone), close to the natural geogenic composition, and anthropogenized areas (Urban and Industrial zones) with a signature close to the $\mathrm{Pb}$ contamination legacy from road traffic.

\section{Conclusion}

Combining both multi-elemental and multi-isotopic compositions of atmospheric metallic contaminants, together with GIS based sampling strategy is assessed in this study and seems to be a promising tool to investigate the fate of metals in the atmosphere and their deposition modes. This especially a requirement 
(a)

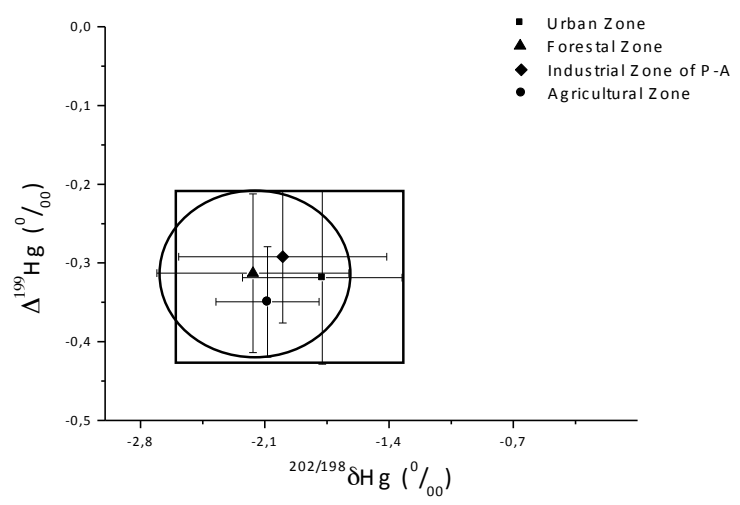

(b)

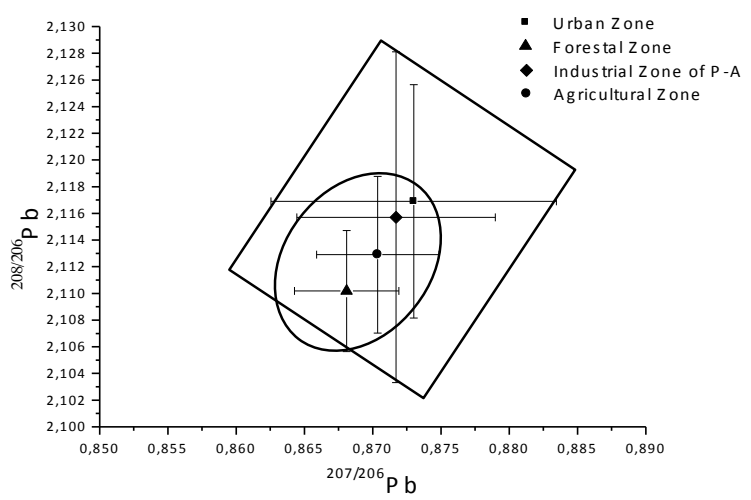

Fig. 3. Plot of isotopic composition in mercury (massindependent fractionation $\Delta^{199} \mathrm{Hg}$ vs. mass-dependent fractionation ${ }^{202 / 198} \delta \mathrm{Hg}$ ) in permil (\%o) (a) and in lead $\left({ }^{208 / 206} \mathrm{~Pb}\right.$ vs. $\left.{ }^{207 / 206} \mathrm{~Pb}\right)(\mathrm{b})$ of the lichens (points represent the median value and the standard deviation for each type of zone). Circle and square represent respectively remote and anthropogenized areas.

when investigating less polluted to remote area in which the tracking of the pollution sources remains very difficult. Mercury and Lead are found to be very specific and complementary elements to be used in such studies.

\section{Acknowledgements}

This work was supported by the CNRS, the University of Pau (UPPA) and the Conseil Général des Pyrénées Atlantiques (CG64).

\section{References}

AFNOR. Détermination d'un indice biologique de lichens épiphytes (IBLE). 2008.

Bergquist BA, Blum JD . The Odds and Even of Mercury Isotopes: Applications of Mass-Dependent and
Mass-Independent Isotope Fractionation. Elements, December 2009; 353-357.

Blum JD, Bergquist BA. Reporting of variations in the natural isotopic composition of mercury. Anal Bioanal Chem, 2007.

Carignan J, Gariépy C. Isotopic composition of epiphytic lichens as a tracer of the sources of atmospheric lead emissions in southern Québec, Canada. Geochimica et Cosmochimica Acta 1995;68:4427-4433.

Carignan J, Estrade N, Sonke JE, Donard, OFX. Odd Isotope Deficits in Atmospheric $\mathrm{Hg}$ Measured in Lichens. Environmental Sicence and Technology $2009 ; 43: 5660-5664$.

CITEPA. source CITEPA/CORALIE/format SECTEN. mise à jour juin $2009 ; 2009.306$ p.

Cloquet, C, Carignan, J, Libourel, J. Atmospheric pollutant dispersion around an urban area using trace metal concentrations and $\mathrm{Pb}$ isotopic compositions in epiphytic lichens. Atmospheric Environment 2006;40:574-587.

EMEP. Heavy Metals: Transboundary Pollution of the Environment. 2011.92 p.

Estrade N, Carignan J, Sonke JE Donard OFX. Measuring $\mathrm{Hg}$ Isotopes in Bio-GeoEnvironnemental Reference Materials. Geostandards and Geoanalitical Research 2010a;34:79-93.

Estrade N, Carignan J, Donard OFX. Isotope Tracing of Mercury Atmospheric Sources in an Urban Area of Northeastern France. Environmental Science and Technology 2010b;44:6062-6067.

Manhès G, Minster JF, Allègre C. Comparative uraniumthorium-lead and rubidium-strontium study of the saint severin amphoterite: consequences for early solar system chronology. Earth and Planetary Science Letters 1978; 39 ed.: 14-24.

Pacyna JM, Pacyna EG, Aas W. Changes of emissions and atmospheric deposition of mercury, lead and cadmium. Atmospheric Environment 2009;43:117127.

Sonke JE. A global model of mass independent mercury stable isotope fractionation . Geochimica et Cosmochimica Acta 2011;75:4577-4590

Szczepaniak K., Biziuk M. Aspects of the biomonitoring studies using mosses and lichens as indicators of metal pollution. Environmental Research 2003;93:221-230.

Veschambre S, et al. Apports atmosphériques des éléments traces métalliques dans la vallée d'Aspe et le tunnel du Somport (Pyrénées-Atlantiques, France) : Niveau de contamination et évaluation des sources d'émissions. Pollution Atmosphérique AvrilSeptembre 2008 ;198-199:215-234. 